\title{
A ESCOLHA DE UM CURSO SUPERIOR DE TECNOLOGIA DA ÁREA DE GESTÃO E NEGÓCIOS: UM ESTUDO SOBRE A DECISÃO DE COMPRA E O COMPORTAMENTO DO CONSUMIDOR
} CHOOSING A HIGHER EDUCATION COURSE IN TECHNOLOGY FROM BUSINESS AND MANAGEMENT AREA: A STUDY OF BUYING DECISION AND CONSUMER BEHAVIOR

\section{Sergio Cricca}

Mestre em Administração pela Universidade Municipal de São Caetano do Sul São Caetano do Sul (SP), Brasil

\section{Roberto Wagner Dias}

Mestre em Administração pela Universidade Municipal de São Caetano do Sul - São Caetano do Sul (SP), Brasil.

\section{Diogo Martins Gonçalves de Morais}

Doutorando da Universidade Municipal de São Caetano do Sul - São Caetano do Sul (SP), Brasil.

\section{Silvio Augusto Minciotti}

Professor do Programa de Pós-Graduação em Administração da Universidade Municipal de São Caetano do Sul - São Caetano do Sul (SP), Brasil.

\section{RESUMO}

O presente estudo tem por objetivo verificar a relevância dos fatores culturais, sociais, pessoais e psicológicos para a escolha de um curso superior de tecnologia da área de gestão e negócios. A pesquisa tem caráter descritivo e foi desenvolvido por meio de uma abordagem quantitativa, utilizando-se de um survey que envolveu 269 estudantes de 4 cursos da área de gestão e negócios e 1 questionário estruturado com 20 variáveis. Na identificação dos fatores, utilizaram-se os resultados das avaliações dos estudantes, em uma escala de 0 a 10, acerca do grau de influência de cada uma das questões na escolha de seu curso superior, o que possibilitou a visualização dos elementos que caracterizam a influência dos fatores culturais, sociais, pessoais e psicológicos na escolha de um curso superior de tecnologia, da área de gestão e negócios, por parte dos estudantes. Conclui-se que o fator pessoal é o que mais influencia os estudantes na escolha de todos os quatro cursos superiores de tecnologia analisados, Sobre a proposta de que a escolha de uma linstituição de ensino para realizar o curso superior na grande maioria dos casos é uma decisão de compra em situação de alto envolvimento.

Palavras-chave: cursos superiores de tecnologia; fatores de influência de compra; comportamento do consumidor.

Endereços dos autores:

Silvio Augusto Minciotti

silvio.minciotti@uscs.edu.br

Sergio Cricca

scricca1@gmail.com
Roberto Wagner Dias

robertowdias@hotmail.com

Diogo Martins Gonçalves de Morais

diogomgm@gmail.com 


\section{ABSTRACT}

The present study aims to determine the relevance of cultural, social, personal and psychological factors discussed in studies to choose a higher educational degree courses in technology, in business and management area. The research has a descriptive character and was developed through a quantitative approach, using a survey that involved 269 students from 4 area courses, business management and a structured questionnaire with 20 variables. In identifying factors, we used the results evaluations of students, on a scale of 0 to 10, the degree of influence of each of the issues in choosing your college degree, which allowed visualization of the elements that characterizes the influence of cultural factors, social, personal and psychological to choose higher educational degree courses in technology, business and management area, by students. In conclusion, the personal factor is what most influences the students in choosing all four higher educational courses in technology, on the proposal that the choice of an educational institution to undertake higher studies in the most of the cases is a buying decision of high involvement.

Keywords: higher educational courses in technology; factors influence purchase; consumer behavior.

\section{INTRODUÇÃO}

De acordo com o Censo da Educação Superior de 2012, realizado anualmente pelo Ministério da Educação (MEC), entre 2000 e 2011, o percentual de ingressantes em cursos superiores de tecnologia (CST) aumentou $547 \%$ em instituições de ensino superior (IES) privadas e públicas do Estado de São Paulo (BRASIL, 2012).

Os cursos superiores de tecnologia se diferenciam dos cursos de bacharelado e licenciatura pela proposta pedagógica, pelo público-alvo e pela infraestrutura utilizada. Segundo a portaria $n^{\circ} 1.024$, de 11 de maio de 2006, estão divididos em 112 graduações diferentes, que são organizadas em 13 eixos tecnológicos (BRASIL, 2006).

Considerando os CST do eixo de gestão e negócios, dados do Censo da Educação Superior mostram que havia 12 instituições oferecendo cursos em 2000, enquanto em 2011 esse número saltou para 3.744, considerando as modalidades presencial e de educação a distância (EAD) (BRASIL, 2012).

Nesse contexto, marcado pelo crescimento do ensino superior no País e pela ampliação dos tipos de cursos superiores, sugere-se que os mantenedores e gestores das IES privadas brasileiras passaram a enfrentar maiores desafios para a manutenção e o desenvolvimento de seus negócios, uma vez que a oferta dos cursos para a comunidade pode ser vista como a prestação de um serviço.

Dessa forma, o entendimento dos fatores de influência dos estudantes, que são os consumidores finais, para a escolha de um curso, e, em especial, dos cursos superiores de tecnologia, se torna objeto de estudo de interesse pela ausência de estudos que envolvam essa modalidade de educação superior específica.

De acordo com Kotler e Keller (2012), o comportamento do consumidor é o estudo de como indivíduos, grupos e organizações selecionam, compram, usam e descartam bens, serviços, ideias ou experiências para satisfazer suas necessidades e seus desejos.

O objetivo deste artigo, portanto, é identificar e analisar a influência dos fatores culturais, sociais, pessoais e psicológicos dos candidatos ao ensino superior, que, nessas circunstâncias, são os consumidores finais na decisão de cursarem um CST em uma IES privada.

No referencial teórico deste artigo, será apresentada a proposta do MEC para os cursos superiores de tecnologia. Além disso, serão abordadas as discussões acerca da decisão de compra do consumidor e apresentados os fatores que influenciam o comportamento do consumidor. Na seção 3 são apresentados 
os procedimentos metodológicos da pesquisa e na seção 4 a análise e discussão dos resultados. Por fim, na seção 5, são apresentadas as considerações finais.

\section{REFERENCIAL TEÓRICO}

\subsection{Cursos Superiores de Tecnologia}

A Lei n 9.394, de 20 de dezembro de 1996, estabelece que a educação profissional e a tecnológica, no cumprimento dos objetivos da educação nacional, integra-se aos diferentes níveis e modalidades de educação e às dimensões do trabalho, da ciência e da tecnologia (BRASIL, 1996). A lei ressalta ainda que os cursos de educação profissional e tecnológica poderão ser organizados por eixos tecnológicos, o que possibilita a construção de diferentes itinerários formativos, observadas as normas dos respectivos sistema e nível de ensino.

O Decreto Federal n²208/97, de 17 de abril de 1997 , estabelece no art. $1^{\circ}$ que a educação profissional tem por objetivos (BRASIL, 1997):

I - promover a transição entre o mundo da escola e o mundo do trabalho, capacitando jovens e adultos com conhecimentos e habilidades gerais e específicas para o exercício da atividade produtiva;

II - proporcionar a formação de profissionais, aptos a exercerem as atividades específicas no trabalho, com escolaridade correspondente ao ensino médio, superior e pós-graduação;

III - especializar, aperfeiçoar e atualizar o trabalho em seus conhecimentos tecnológicos;

IV - qualificar, reprofissionalizar e atualizar jovens e adultos trabalhadores, com qualquer nível de escolaridade, visando sua inserção e melhor desempenho no exercício do trabalho.

A Portaria MEC n 10, de 28 de julho de 2006, aprova o Catálogo Nacional dos Cursos Superiores de Tecnologia, elaborado pela Secretaria de Educação Profissional e Tecnológica do Ministério da Educação, e fixa a carga horária e finalidade dos 112 cursos, que são organizados em 13 eixos tecnológicos, a saber: Ambiente e Saúde, com 6 cursos; Apoio Escolar, com 1 curso; Controle e Processos Industriais, com 12 cursos; Gestão e Negócios, com 12 cursos; Hospitalidade e Lazer, com 5 cursos; Informação e Comunicação, com 12 cursos; Infraestrutura, com 11 cursos; Militar, com 6 cursos; Produção Alimentícia, com 6 cursos; Produção cultural e Design, com 14 cursos; Produção Industrial, com 12 cursos; Recursos Naturais, com 10 cursos; e Segurança, com 5 cursos (BRASIL, 2006).

Conforme o Art. $1^{\circ}$ da Resolução CNE/CP 03, de 18 de dezembro de 2002, a educação profissional de nível tecnológico, integrada às diferentes formas de educação, ao trabalho, à ciência e à tecnologia, objetiva garantir aos cidadãos o direito à aquisição de competências profissionais que os tornem aptos para a inserção em setores profissionais nos quais haja utilização de tecnologias (BRASIL, 2002).

O Art. 2 da mesma resolução estabelece que os cursos de educação profissional de nível tecnológico serão designados como cursos superiores de tecnologia e deverão:

I - incentivar o desenvolvimento da capacidade empreendedora e da compreensão do processo tecnológico, em suas causas e efeitos;

II - incentivar a produção e a inovação científicotecnológica, e suas respectivas aplicações no mundo do trabalho;

III - desenvolver competências profissionais tecnológicas, gerais e específicas, para a gestão de processos e a produção de bens e serviços;

IV - propiciar a compreensão e a avaliação dos impactos sociais, econômicos e ambientais resultantes da produção, gestão e incorporação de novas tecnologias;

$\checkmark$ - promover a capacidade de continuar aprendendo e de acompanhar as mudanças nas condições de trabalho, bem como propiciar o prosseguimento de estudos em cursos de pós-graduação;

VI - adotar a flexibilidade, a interdisciplinaridade, a contextualização e a atualização permanente dos cursos e seus currículos; 
VII - garantir a identidade do perfil profissional de conclusão de curso e da respectiva organização curricular.

Diante da equiparação dos CST aos cursos de bacharelados e licenciaturas, o nível superior de escolaridade conferido aos cidadãos passou a entrar no rol de serviços oferecidos pelas instituições de ensino privadas, com o diferencial de conferir a titulação em um período inferior aos cursos de bacharelado e licenciatura.

\subsection{O processo de decisão de compras do consumidor}

Diversos autores concordam que o ensino é uma prestação de serviço (LOVELOCK, 2006; HOFFMAN, 2003; ZEITHAML; BITNER, 2003; LAS CASAS, 2007; BATESON; HOFFMAN, 2001), e a escolha de uma instituição de ensino para realizar o curso superior na grande maioria dos casos é uma decisão de compra em situação de alto envolvimento.

O nível de envolvimento do consumidor é o fator que mais influencia a quantidade de esforços que serão despendidos na decisão de compra, determinando, assim, o tipo de processo de decisão que será empregado.

\section{Com o objetivo de}

analisar como os consumidores ordenam os fatos e as influências para tomar decisões que são lógicas e consistentes para eles durante o processo de compra", Engel, Blackwell e Miniard, (2005, p. 73)

apresentam sete estágios de tomada de decisão, conforme pode ser observado na Figura 1: reconhecimento da necessidade, busca de informações, avaliação de alternativas na pré-compra, compra, consumo, avaliação pós-consumo e descarte.
O primeiro estágio, reconhecimento da necessidade, ocorre com a "percepção da diferença entre o estado desejado das coisas e o estado real, suficiente para estimular e ativar o processo de decisão". Portanto, quando a satisfação com o estado real diminui ou quando o nível de estado desejado aumenta, o consumidor reconhece a existência de um problema e se sente impulsionado ao consumo (ENGEL, BLACKWELL E MINIARD, 2005).

Ainda na visão dos autores, o segundo estágio, busca de informações, representa a busca de conhecimentos armazenados na memória ou a aquisição de informações do ambiente, relacionados à satisfação de suas necessidades. O estágio seguinte, a avaliação pré-compra, abrange o modo como as alternativas de escolha são avaliadas.

No quarto estágio, a compra, a principal pergunta a ser respondida é "se a compra deve ser feita ou não", para, em seguida: "quando comprar", "que tipo de produto e marca comprar", "em qual tipo de varejista e em qual varejista específico comprar" e "como pagar" (ENGEL, BLACKWELL E MINIARD, 2005).

No estágio cinco, após a compra, o produto é consumido. Segundo os autores, consumo é o uso do produto adquirido pelo consumidor. Sugerem ainda como pontos principais do processo de consumo: o momento, o local, a maneira como ocorre, e a quantidade consumida. Esses autores também comentam que durante e após o consumo da alternativa adquirida, no estágio seis, conhecido como avaliação pós-consumo, os consumidores irão analisar se a alternativa escolhida foi satisfatória ou não.

Finalmente, os autores definem o estágio sete, de descarte, como desfazer-se do bem ao jogá-lo fora diretamente ou por meio de troca, doação, reciclagem ou revenda.

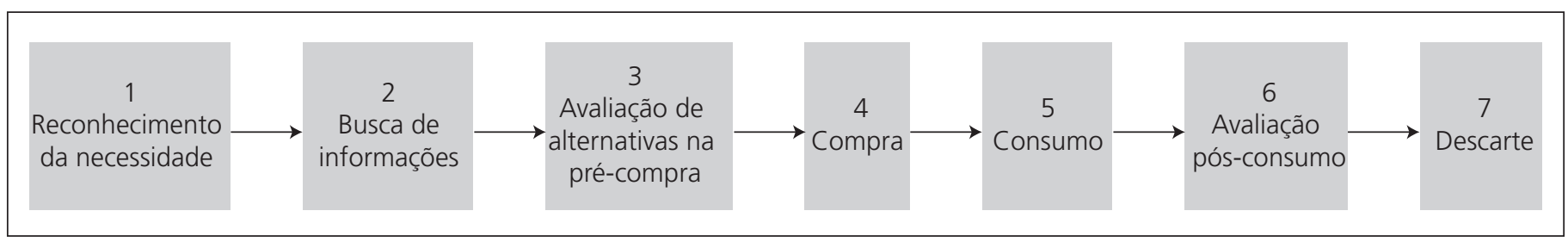

Fonte: Adaptado de Engel, Blackwell e Miniard (2005).

Figura 1: Estágios do processo de decisão de compra. 
Segundo Kotler e Keller (2012), o comportamento do consumidor é influenciado, principalmente, por quatro fatores: culturais (cultura, subcultura e classe social), sociais (grupos de referência, família, papéis e status), pessoais (idade e estágio no ciclo de vida, ocupação, situação econômica, estilo de vida, personalidade e autoimagem) e psicológicos (motivação, percepção, aprendizagem, crenças e atitudes).

Frequentemente, os profissionais de marketing usam as características culturais para segmentar os mercados globais e anunciar e vender produtos para diferentes mercados. Exemplificando, o McDonald's leva em consideração a comida e os hábitos alimentares de cada cultura para adequar seu cardápio.

A cultura tem um profundo efeito em como e porque as pessoas compram e consomem produtos e serviços. Ela afeta os produtos específicos que as pessoas compram, assim como a estrutura de consumo, a tomada de decisão e comunicação na sociedade. (BLACKWELL, MINIARD e ENGEL, 2005, p. 3).

Nessa linha, Kotler e Keller (2002) definem a cultura como um conjunto de valores, percepções e preferências determinantes do comportamento e dos desejos de uma pessoa. Além disso, classificam as subculturas como divisões hierarquicamente ordenadas em uma sociedade que compartilham valores, interesses e comportamentos similares, tais como nacionalidades, religiões, grupos raciais e regiões geográficas e a classe social.

Quanto aos fatores sociais, há destaque aos grupos de referência, que são todos os grupos que têm alguma influência direta ou indireta sobre as atitudes ou o comportamento de uma pessoa. Alguns deles são grupos primários, como família, amigos, vizinhos e colegas de trabalho, com os quais se interage de modos contínuo e informal. Também existem grupos secundários, como grupos religiosos e profissionais ou associações de classe, que costumam ser mais formais e exigir menos interação contínua. Além disso, entre os fatores sociais, os autores chamam a atenção para os papéis assumidos, como atividades que uma pessoa deve desempenhar e o status associado a cada uma delas.

Nos fatores pessoais, são consideradas a idade, pois as pessoas compram bens diferentes ao longo de sua vida, a ocupação e situação econômica, pois a situação no emprego também influencia o padrão de consumo de uma pessoa, o estilo de vida, definido como o padrão de vida expresso por atividades, interesses e opiniões, além da personalidade e da autoimagem, uma vez que toda pessoa tem características psicológicas distintas que influenciam seu comportamento de compra.

Por fim, há fatores psicológicos, que, segundo os autores, compreende a motivação, que está relacionada com a intensidade da necessidade. Algumas necessidades são biogênicas, surgem de estados de tensão fisiológicos, como fome, sede ou desconforto. Outras necessidades são psicológicas, decorrentes de estados de tensão psicológicos, como necessidade de reconhecimento, estima ou integração. Além disso, os fatores psicológicos envolvem a percepção, que é o processo pelo qual alguém seleciona, organiza e interpreta as informações recebidas para criar uma imagem significativa do mundo, a aprendizagem, definida como as mudanças no comportamento de uma pessoa decorrentes da sua experiência, as emoções, como a reação do consumidor não cognitiva e racional, e por fim a memória, que é o conjunto de todas as informações e experiências acumuladas pelas pessoas ao longo de suas vidas podem.

A análise desses fatores fornece orientação para atrair e servir mais eficazmente os compradores.

\section{ASPECTOS METODOLÓGICOS}

Para atender ao objetivo proposto nesta pesquisa, que é identificar e analisar a influência dos fatores culturais, sociais, pessoais e psicológicos dos candidatos ao ensino superior, que nesta circunstância são os consumidores finais na decisão de cursarem um CST em uma IES privada, optou-se por uma abordagem quantitativa de caráter descritivo-exploratório.

Como desenho mais apropriado, optou-se por uma survey interseccional, na qual os dados são coletados em um único momento de uma amostra selecionada. Os questionários foram respondidos na presença dos pesquisadores entre agosto e novembro de 2013. 
A amostra utilizada foi não probabilística e por conveniência dos pesquisadores, composta por 269 alunos matriculados de quatro CSTs de uma instituição de ensino superior, sendo 152 alunos do CST em Relações Humanas, 41 do CST em Finanças, 46 do CST em Logística e 30 do CST em Marketing.

Depois da coleta de dados, realizou-se a análise dos dados por meio do SPSS for Windows (Statistic Package for Social Science), na versão 19, onde foram utilizados os procedimentos de distribuição de frequência e estatística descritiva.

As questões foram elaboradas após revisão da literatura sobre comportamento do consumidor e consulta aos especialistas da área educacional.

O questionário buscou descrever o perfil dos respondentes, com informações como o curso escolhido, o gênero, a idade, o estado civil e informações sobre experiência de trabalho, renda familiar e escolaridade do pai, além de 20 questões sobre a escolha do curso, apresentadas no Quadro1, que foram utilizadas para atender ao objetivo deste estudo, que era identificar quais as características dos consumidores, com vista aos fatores culturais, sociais, pessoais e psicológicos, propostos por Kotler e Keller (2012), que influenciaram os candidatos ao ensino superior, na decisão por um CST da área de gestão e negócios.

Na identificação dos fatores, utilizaram-se os resultados das avaliações dos estudantes, em uma escala de 0 a 10, do grau de influência de cada uma das questões na escolha de seu curso superior.

\section{ANÁLISE DOS RESULTADOS}

Responderam o questionário de pesquisa 269 alunos que ingressaram no primeiro semestre dos quatro CST da área de gestão e negócios oferecidos pela IES pesquisada, a saber: CST em Recursos Humanos (RH), Finanças, Logística e Marketing.

Dos quatro cursos envolvidos, observa-se a predominância de mulheres nos cursos de Finanças e $\mathrm{RH}$, enquanto no curso de Logística há maioria de homens. Já no CST em Marketing a diferença entre o número de homens e mulheres é menos acentuada.
Quadro 1: Questões acerca da escolha do curso superior de tecnologia.

\begin{tabular}{|c|c|}
\hline Q1 & $\begin{array}{c}\text { Para minha família será } \\
\text { importante que eu tenha curso superior. }\end{array}$ \\
\hline Q2 & $\begin{array}{l}\text { Para quem mora em região metropolitana, como eu, } \\
\text { precisa de um curso superior para ter sucesso na vida. }\end{array}$ \\
\hline Q3 & $\begin{array}{l}\text { Na minha classe social, cursar uma faculdade é } \\
\text { necessário para se obter reconhecimento. }\end{array}$ \\
\hline Q4 & $\begin{array}{c}\text { Ter um diploma universitário é um símbolo de realização } \\
\text { para quem batalhou para subir na vida. }\end{array}$ \\
\hline Q5 & A escolha foi influenciada pela minha família. \\
\hline Q6 & Meu ciclo de amizade está cursando uma faculdade. \\
\hline Q7 & Foi i \\
\hline Q8 & $\begin{array}{l}\text { Acredito que este curso possa ser uma maneira de } \\
\text { melhorar minha posição social. }\end{array}$ \\
\hline Q9 & $\begin{array}{l}\text { Pretendo ser promovido na empresa onde trabalho e } \\
\text { acho que este curso me possibilitará isso. }\end{array}$ \\
\hline Q10 & Estou na idade correta para cursar uma faculdade. \\
\hline Q11 & $\begin{array}{c}\text { Estar na faculdade tem tudo a ver com a minha maneira } \\
\text { de viver. }\end{array}$ \\
\hline Q12 & $\begin{array}{l}\text { O tempo de duração do curso influenciou a minha } \\
\text { decisão. }\end{array}$ \\
\hline Q13 & a condição de vida. \\
\hline Q14 & $\begin{array}{l}\text { Melhorando minha condição profissional, vou poder } \\
\text { comprar as coisas com que sonho. }\end{array}$ \\
\hline Q15 & $\begin{array}{c}\text { Estou confiante que ao cursar esse curso, permitirá que } \\
\text { eu alcance meus objetivos. }\end{array}$ \\
\hline Q16 & $\begin{array}{c}\text { Observei diversas vezes as propagandas sobre a } \\
\text { faculdade e elas me convenceram a me matricular neste } \\
\text { curso. }\end{array}$ \\
\hline Q17 & $\begin{array}{l}\text { Conheço pessoas que cursaram esse curso e } \\
\text { conseguiram melhorar sua situação profissional. }\end{array}$ \\
\hline Q18 & $\begin{array}{c}\text { Existem momentos em que temos que tomar uma } \\
\text { atitude, para não nos arrependermos depois. Senti que } \\
\text { tinha chegado a minha hora. }\end{array}$ \\
\hline Q19 & $\begin{array}{l}\text { A vida me ensinou que sem preparação técnica fica } \\
\text { difícil o desenvolvimento profissional. }\end{array}$ \\
\hline Q20 & $\begin{array}{c}\text { Escolhi esse curso por } \\
\text { ser mais acessível do que os outros. }\end{array}$ \\
\hline
\end{tabular}

A Tabela 1 apresenta a distribuição de todos os quatro cursos envolvidos.

Em todos os quatro cursos, pode-se observar que a renda mensal familiar média se encontra na faixa de $\mathrm{R} \$ 1.244,00$ a $R \$ 2.488,00$. No entanto, há destaque para o curso de Finanças, que apresenta o maior contingente na faixa de renda superior a $R \$ 6.220,00$, 
Tabela 1: Gênero dos entrevistados.

\begin{tabular}{l|c|c|c|c|c|c|c|c|c|c}
\hline \multirow{2}{*}{ Gênero } & \multicolumn{2}{|c|}{ RH } & & Finanças & \multicolumn{2}{c|}{ Logística } & \multicolumn{2}{c|}{ Marketing } & \multicolumn{2}{c}{ Total } \\
\cline { 2 - 13 } & Freq. & $\%$ & Freq. & $\%$ & Freq. & $\%$ & Freq. & $\%$ & Freq. & $\%$ \\
\hline Masculin o & 19 & 12,5 & 11 & 26,8 & 33 & 71,7 & 13 & 43,3 & 776 & 228,3 \\
\hline Feminino & 133 & 87,5 & 30 & 73,2 & 12 & 26,1 & 17 & 56,7 & 1192 & 771,4 \\
\hline Não informado & & & & & 1 & 2,2 & & & 1 & 0,03 \\
\hline Total & 152 & 100,0 & 41 & 100,0 & 46 & 100,0 & 30 & 100,0 & 269 & 100,0 \\
\hline
\end{tabular}

Tabela 2: Rendimento mensal familiar.

\begin{tabular}{l|c|c|c|c|c|c|c|c|c|c}
\hline \multirow{2}{*}{ R\$ } & \multicolumn{2}{|c|}{ RH } & \multicolumn{2}{c|}{ Finanças } & \multicolumn{2}{c|}{ Logística } & \multicolumn{2}{c|}{ Marketing } & \multicolumn{2}{c}{ Total } \\
\cline { 2 - 13 } & Freq. & $\%$ & Freq. & $\%$ & Freq. & $\%$ & Freq. & $\%$ & Freq. & $\%$ \\
\hline 0 a 1.244 & 29 & 19,1 & 3 & 7,3 & 9 & 19,6 & 4 & 13,3 & 45 & 16,7 \\
\hline 1.244 a 2.488 & 75 & 49,3 & 12 & 29,3 & 20 & 43,5 & 10 & 33,3 & 117 & 43,5 \\
\hline 2.488 a 6.220 & 38 & 25,0 & 17 & 41,5 & 14 & 30,4 & 7 & 23,3 & 76 & 28,3 \\
\hline 6.220 a 12.440 & 2 & 1,3 & 9 & 20 & 2 & 4,3 & 8 & 26,7 & 21 & 7,8 \\
\hline Maior do que 12.440,00 & 2 & 1,3 & 0 & 0 & 0 & 0 & 0 & 0 & 2 & 0,8 \\
\hline Não informado & 6 & 3,9 & 0 & 0 & 1 & 2,2 & 1 & 3,3 & 8 & 2,9 \\
\hline Total & 152 & 100,0 & 41 & 100,0 & 46 & 100,0 & 30 & 100,0 & 269 & 100,0 \\
\hline
\end{tabular}

seguido pelo curso de Marketing. A Tabela 2 apresenta a distribuição de valores.

Outra questão retratada na pesquisa foi a idade dos estudantes que ingressaram nos CST. Em todos os cursos observou-se que no mínimo $60 \%$ dos estudantes já tinham mais do que 22 anos, confirmando o perfil do público para o qual foi desenhada a proposta dos CST, que eram trabalhadores em busca de atualização, conforme prescrito no decreto Federal n 2208/97 de 17 de abril de 1997, que estabelece, no art.1º, os objetivos da educação profissional. A Tabela 3 apresenta tal distribuição.

Observa-se nos dados sobre o estado civil dos estudantes a predominância de solteiros, porém com um número razoável de casados nos cursos de Recursos Humanos, seguido pelos cursos de Logística e Finanças. Esses números caminham na direção do constatado pela idade dos estudantes, que se encontram na faixa etária acima de 22 anos. A Tabela 4 apresenta os números de solteiros e casados.

No que se refere ao grau de instrução do pai, observa-se, na Tabela 5, uma mudança no perfil dessa nova geração, que não apresenta mais do que 3\% dos pais com ensino superior, com a exceção do curso de Marketing, que tinha 13,3\% dos pais com grau de instrução superior.

No que se refere à condição de ocupação atual, constatou-se que o número de alunos que nunca trabaIhou não passa de $20 \%$, o que é esperado para o perfil dos estudantes de um CST. É interessante observar, na Tabela 6, que os cursos de Logística e Finanças são os únicos cursos em que o percentual de alunos que já trabalham na área ou em áreas correlatas supera $50 \%$.

No que se refere aos fatores de escolha prescritos no referencial teórico deste estudo, a saber, os fatores cultural, social, pessoal e psicológico, observou-se que, de forma geral, o fator pessoal é o que mais influencia os estudantes na escolha dos cursos superiores de tecnologia, seguido do cultural, do psicológico e do social, nessa ordem. A Tabela 7 apresenta a pontuação obtida pelos fatores ao considerar os quatro cursos envolvidos na pesquisa.

Ao relacionar os estudantes de cada um dos cursos com os fatores constituintes deste estudo, 
Tabela 3: Idade dos estudantes.

\begin{tabular}{|c|c|c|c|c|c|c|c|c|c|c|}
\hline \multirow{2}{*}{ Idade } & \multicolumn{2}{|c|}{ RH } & \multicolumn{2}{|c|}{ Finanças } & \multicolumn{2}{|c|}{ Logística } & \multicolumn{2}{|c|}{ Marketing } & \multicolumn{2}{|c|}{ Total } \\
\hline & Freq. & $\%$ & Freq. & $\%$ & Freq. & $\%$ & Freq. & $\%$ & Freq. & $\%$ \\
\hline 17 a 22 & 50 & 33 & 10 & 24 & 5 & 11 & 10 & 33,3 & 75 & 27,9 \\
\hline 22 a 27 & 46 & 30 & 13 & 32 & 12 & 26 & 14 & 46,7 & 85 & 31,6 \\
\hline 27 a 32 & 25 & 16 & 9 & 22 & 11 & 24 & 3 & 10 & 48 & 17,8 \\
\hline 32 a 37 & 19 & 13 & 3 & 7 & 13 & 28 & 3 & 10 & 38 & 14,1 \\
\hline Acima de 37 & 12 & 8 & 6 & 15 & 5 & 11 & 0 & 0 & 23 & 8,6 \\
\hline Total & 152 & 100 & 41 & 100 & 46 & 100 & 30 & 100 & 269 & 100,0 \\
\hline
\end{tabular}

Tabela 4: Estado civil dos estudantes.

\begin{tabular}{l|c|c|c|c|c|c|c|c|c|c}
\hline \multirow{2}{*}{ Estado civil } & \multicolumn{2}{|c|}{ RH } & \multicolumn{2}{c|}{ Finanças } & \multicolumn{2}{c|}{ Logística } & \multicolumn{2}{c|}{ Marketing } & \multicolumn{2}{c}{ Total } \\
\cline { 2 - 13 } & Freq. & $\%$ & Freq. & $\%$ & Freq. & $\%$ & Freq. & $\%$ & Freq. & $\%$ \\
\hline Casado & 39 & 25,7 & 15 & 36,6 & 18 & 39,1 & 3 & 10,0 & 75 & 27,9 \\
\hline Solteiro & 90 & 59,2 & 21 & 51,2 & 19 & 41,3 & 23 & 76,7 & 153 & 56,9 \\
\hline Outros & 7 & 4,6 & 1 & 2,4 & 5 & 10,9 & 1 & 3,3 & 14 & 5,2 \\
\hline Não informado & 16 & 10,5 & 4 & 9,8 & 4 & 8,7 & 3 & 10,0 & 27 & 10,0 \\
\hline Total & 152 & 100 & 41 & 100 & 46 & 100 & 30 & 100 & 269 & 100,0 \\
\hline
\end{tabular}

Tabela 5: Grau de instrução do pai.

\begin{tabular}{l|c|c|c|c|c|c|c|c|c|c}
\hline \multirow{2}{*}{ Níveis } & \multicolumn{2}{|c|}{ RH } & \multicolumn{2}{c|}{ Finanças } & \multicolumn{2}{c|}{ Logística } & \multicolumn{2}{c|}{ Marketing } & \multicolumn{2}{c}{ Total } \\
\cline { 2 - 13 } & Freq. & $\%$ & Freq. & $\%$ & Freq. & $\%$ & Freq. & $\%$ & Freq. & $\%$ \\
\hline Ensino fundamental & 91 & 59,9 & 24 & 58,5 & 22 & 47,8 & 13 & 43,3 & 150 & 55,8 \\
\hline Ensino médio & 40 & 26,3 & 10 & 24,4 & 14 & 30,4 & 10 & 33,3 & 74 & 27,5 \\
\hline Ensino superior & 4 & 2,6 & 1 & 2,4 & 1 & 2,2 & 4 & 13,3 & 10 & 3,7 \\
\hline Nenhum & 10 & 6,6 & 5 & 12,2 & 7 & 15,2 & 2 & 6,7 & 24 & 8,9 \\
\hline Não informado & 7 & 4,6 & 1 & 2,4 & 2 & 4,3 & 1 & 3,3 & 11 & 4,1 \\
\hline Total & 152 & 100,0 & 41 & 100,0 & 46 & 100,0 & 30 & 100,0 & 269 & 100,0 \\
\hline
\end{tabular}

Tabela 6: Condição de ocupação atual.

\begin{tabular}{l|c|c|c|c|c|c|c|c|c|c}
\hline \multirow{2}{*}{ Níveis } & \multicolumn{2}{|c|}{ RH } & \multicolumn{2}{c|}{ Finanças } & \multicolumn{2}{c|}{ Logística } & \multicolumn{2}{c|}{ Marketing } & \multicolumn{2}{c}{ Total } \\
\cline { 2 - 12 } & Freq. & $\%$ & Freq. & $\%$ & Freq. & $\%$ & Freq. & $\%$ & Freq. & $\%$ \\
\hline Não, nunca trabalhei & 17 & 11 & 5 & 12 & 8 & 17 & 3 & 10 & 33 & 12,3 \\
\hline $\begin{array}{l}\text { Sim, na área do curso ou } \\
\text { em área correlata }\end{array}$ & 33 & 22 & 27 & 66 & 26 & 57 & 12 & 40 & 98 & 36,4 \\
\hline Sim, fora da área do curso & 95 & 63 & 9 & 22 & 11 & 24 & 15 & 50 & 130 & 48,3 \\
\hline Não informado & 7 & 5 & 0 & & 1 & 2 & 0 & & 8 & 3,0 \\
\hline Total & 152 & 100 & 41 & 100 & 46 & 100 & 30 & 100 & 269 & 100,0 \\
\hline
\end{tabular}


constatou-se que os estudantes do curso de Marketing são mais influenciados por variáveis do fator cultural, seguidos dos estudantes dos cursos de $\mathrm{RH}$, Logística e Finanças, nessa ordem. A Tabela 8 apresenta tais resultados.

No que se refere ao fator cultural, pode-se também observar que, embora os estudantes não acreditem muito na influência da família na escolha do curso, há forte preocupação com a sua imagem perante seus familiares.

Quanto ao fator social, também se verificou que os estudantes do curso de Marketing são mais influenciados por variáveis relacionadas às questões sociais,

Tabela 7: Influência dos fatores na escolha dos estudantes.

\begin{tabular}{l|c|c}
\hline Fatores & $\begin{array}{c}\text { Pontuação obtida } \\
\text { (máximo: 13.450) }\end{array}$ & $\%$ \\
\hline Pessoal & 11.589 & 86 \\
\hline Cultural & 10.862 & 81 \\
\hline Psicológico & 10.014 & 74 \\
\hline Social & 9.223 & 69 \\
\hline
\end{tabular}

seguidos dos estudantes dos cursos de Logística, RH e Finanças, nessa ordem. As variáveis mais influentes são apresentadas na Tabela 9.

É possível observar ainda, no âmbito social, destaque para a crença que a escolha do curso está associada à mudança na posição social dos estudantes.

No que se refere ao fator pessoal, constatou-se que os estudantes do curso de RH são mais influenciados por variáveis constituintes desse fator, seguidos dos estudantes dos cursos de Marketing, Logística e Finanças. As variáveis mais influentes são apresentadas na Tabela 10.

É interessante observar no fator pessoal que a expectativa de mudança de vida e a crença de que o curso permitirá a realização de sonhos são as variáveis mais influentes na escolha dos estudantes.

Por fim, observou-se que os estudantes do curso de Marketing são mais influenciados por variáveis constituintes do fator psicológico, seguidos dos estudantes dos cursos de Logística, RH e Finanças, nessa ordem. As variáveis mais influentes são apresentadas na Tabela 11.

Tabela 8: Influência do fator cultural na escolha dos estudantes.

\begin{tabular}{|c|c|c|c|c|c|c|c|c|c|c|}
\hline \multirow{4}{*}{ VARIÁVEIS } & \multicolumn{8}{|c|}{ CURSOS } & \multirow{3}{*}{\multicolumn{2}{|c|}{$\begin{array}{c}\text { TOTAL } \\
\text { Máximo: } 2.690\end{array}$}} \\
\hline & \multirow{2}{*}{\multicolumn{2}{|c|}{$\begin{array}{c}\text { RH } \\
\text { Máximo:1520 }\end{array}$}} & \multirow{2}{*}{\multicolumn{2}{|c|}{$\begin{array}{c}\text { FINANÇAS } \\
\text { Máximo: } 410\end{array}$}} & \multirow{2}{*}{\multicolumn{2}{|c|}{$\begin{array}{c}\text { LOGÍSTICA } \\
\text { Máximo: } 460\end{array}$}} & \multirow{2}{*}{\multicolumn{2}{|c|}{$\begin{array}{l}\text { MARKETING } \\
\text { Máximo: } 300\end{array}$}} & & \\
\hline & & & & & & & & & & \\
\hline & Soma & $\%$ & Soma & $\%$ & Soma & $\%$ & Soma & $\%$ & Soma & $\%$ \\
\hline $\begin{array}{l}\text { Para minha família será importante } \\
\text { que eu tenha curso superior. }\end{array}$ & 11.375 & 990 & 3357 & 887 & 4417 & 991 & 2283 & 994 & 2.432 & 990 \\
\hline $\begin{array}{l}\text { Para quem mora em região } \\
\text { metropolitana, como eu, preciso de } \\
\text { um curso superior para ter sucesso na } \\
\text { vida. }\end{array}$ & 11.326 & 887 & 3332 & 881 & 3388 & 884 & 2283 & 994 & 2.329 & 887 \\
\hline $\begin{array}{l}\text { Na minha classe social, cursar uma } \\
\text { faculdade é necessário para se obter } \\
\text { reconhecimento. }\end{array}$ & 11.309 & 886 & 3355 & 887 & 3376 & 882 & 2256 & 885 & 2.296 & 885 \\
\hline $\begin{array}{l}\text { Ter um diploma universitário é um } \\
\text { símbolo de realização para quem } \\
\text { batalhou para subir na vida. }\end{array}$ & 11.412 & 993 & 3353 & 886 & 3396 & 886 & 2265 & 888 & 2.426 & 990 \\
\hline $\begin{array}{l}\text { A escolha foi influenciada pela minha } \\
\text { família. }\end{array}$ & 7750 & 449 & 2211 & 551 & 2245 & 553 & 1173 & 558 & 1.379 & 551 \\
\hline Total & 6.172 & 81 & 1.608 & 78 & 1.822 & 79 & 1.260 & 84 & 10.862 & 81 \\
\hline Máximo & 7.600 & & 2.050 & & 2.300 & & 1.500 & & 13.450 & \\
\hline
\end{tabular}

Nota: O termo "soma" refere-se à pontuação obtida por cada variável, considerando uma escala de 10 pontos e o total de respondentes de cada um dos cursos. 
Tabela 9: Influência do fator social na escolha dos estudantes.

\begin{tabular}{|c|c|c|c|c|c|c|c|c|c|c|}
\hline \multirow{4}{*}{ VARIÁVEIS } & \multicolumn{8}{|c|}{ CURSOS } & \multirow{3}{*}{\multicolumn{2}{|c|}{$\begin{array}{c}\text { TOTAL } \\
\text { Máximo: } 2.690\end{array}$}} \\
\hline & \multirow{2}{*}{\multicolumn{2}{|c|}{$\begin{array}{c}\mathrm{RH} \\
\text { Máximo: } 1.520\end{array}$}} & \multirow{2}{*}{\multicolumn{2}{|c|}{$\begin{array}{c}\text { FINANÇAS } \\
\text { Máximo: } 410\end{array}$}} & \multirow{2}{*}{\multicolumn{2}{|c|}{$\begin{array}{c}\text { LOGÍSTICA } \\
\text { Máximo: } 460\end{array}$}} & \multirow{2}{*}{\multicolumn{2}{|c|}{$\begin{array}{l}\text { MARKETING } \\
\text { Máximo: } 300\end{array}$}} & & \\
\hline & & & & & & & & & & \\
\hline & Soma & $\%$ & Soma & $\%$ & Soma & $\%$ & Soma & $\%$ & Soma & $\%$ \\
\hline $\begin{array}{l}\text { Meu ciclo de amizade está cursando } \\
\text { uma faculdade. }\end{array}$ & 931 & 61 & 221 & 54 & 279 & 61 & 215 & 72 & 1.646 & 61 \\
\hline Foi influência de colegas de trabalho. & 636 & 42 & 212 & 52 & 207 & 45 & 155 & 52 & 1.210 & 45 \\
\hline $\begin{array}{l}\text { Acredito que este curso possa ser uma } \\
\text { maneira de melhorar minha posição } \\
\text { social. }\end{array}$ & 1.384 & 91 & 360 & 88 & 407 & 88 & 279 & 93 & 2.430 & 90 \\
\hline $\begin{array}{l}\text { Pretendo ser promovido na empresa } \\
\text { onde trabalho e acho que este curso } \\
\text { me possibilitará isso. }\end{array}$ & 1.142 & 75 & 310 & 76 & 479 & 104 & 257 & 86 & 2.188 & 81 \\
\hline $\begin{array}{l}\text { Estou na idade correta para cursar } \\
\text { uma faculdade. }\end{array}$ & 1.020 & 67 & 243 & 59 & 258 & 56 & 228 & 76 & 1.749 & 65 \\
\hline Total & 5.113 & 67 & 1.346 & 66 & 1.630 & 71 & 1.134 & 76 & 9.223 & 69 \\
\hline Máximo & 7.600 & & 2.050 & & 2.300 & & 1.500 & & 13.450 & \\
\hline
\end{tabular}

Nota: O termo "soma" refere-se à pontuação obtida por cada variável, considerando uma escala de 10 pontos e o total de respondentes de cada um dos cursos.

Tabela 10: Influência do fator pessoal na escolha dos estudantes.

\begin{tabular}{|c|c|c|c|c|c|c|c|c|c|c|}
\hline \multirow{4}{*}{ VARIÁVEIS } & \multicolumn{8}{|c|}{ CURSOS } & \multirow{3}{*}{\multicolumn{2}{|c|}{$\begin{array}{c}\text { TOTAL } \\
\text { Máximo: } 2.690\end{array}$}} \\
\hline & \multirow{2}{*}{\multicolumn{2}{|c|}{$\begin{array}{c}\text { RH } \\
\text { Máximo: } 1.520\end{array}$}} & \multirow{2}{*}{\multicolumn{2}{|c|}{$\begin{array}{c}\text { FINANÇAS } \\
\text { Máximo: } 410\end{array}$}} & \multirow{2}{*}{\multicolumn{2}{|c|}{$\begin{array}{c}\text { LOGÍSTICA } \\
\text { Máximo: } 460\end{array}$}} & \multirow{2}{*}{\multicolumn{2}{|c|}{$\begin{array}{l}\text { MARKETING } \\
\text { Máximo: } 300\end{array}$}} & & \\
\hline & & & & & & & & & & \\
\hline & Soma & $\% \%$ & Soma & $\% \%$ & Soma & $\% \%$ & Soma & $\% \%$ & Soma & $\% \%$ \\
\hline $\begin{array}{l}\text { Estar na faculdade tem tudo a ver } \\
\text { com a minha maneira de viver. }\end{array}$ & 1.133 & 75 & 267 & 65 & 342 & 74 & 247 & 82 & 1.989 & 74 \\
\hline $\begin{array}{l}\text { O tempo de duração do curso } \\
\text { influenciou na minha decisão. }\end{array}$ & 1.123 & 74 & 353 & 86 & 339 & 74 & 227 & 76 & 2.042 & 76 \\
\hline $\begin{array}{l}\text { Preciso melhorar minha condição de } \\
\text { vida. }\end{array}$ & 1.514 & 100 & 372 & 91 & 423 & 92 & 272 & 91 & 2.581 & 96 \\
\hline $\begin{array}{l}\text { Melhorando minha condição } \\
\text { profissional, vou poder comprar as } \\
\text { coisas com que sonho. }\end{array}$ & 1.437 & 95 & 352 & 86 & 404 & 88 & 265 & 88 & 2.458 & 91 \\
\hline $\begin{array}{l}\text { Estou confiante que ao cursar esse } \\
\text { curso, permitirá que eu alcance meus } \\
\text { objetivos. }\end{array}$ & 1.432 & 94 & 378 & 92 & 429 & 93 & 280 & 93 & 2.519 & 94 \\
\hline Total & 6.639 & 87 & 1.722 & 84 & 1.937 & 84 & 1.291 & 86 & 11.589 & 86 \\
\hline Máximo & 7.600 & & 2.050 & & 2.300 & & 1.500 & & 13.450 & \\
\hline
\end{tabular}

Nota: O termo "soma" refere-se à pontuação obtida por cada variável, considerando uma escala de 10 pontos e o total de respondentes de cada um dos cursos.

Observa-se que a crença de que o curso possibilitará uma melhor preparação para a vida profissional se mostra como a variável mais influente entre os elementos do fator psicológico. Além disso, constata-se uma menor influência das variáveis associadas às propagandas e às facilidades de acesso, enquanto influenciadores da escolha.

\section{CONSIDERAÇÕES FINAIS}

Por meio das definições de Kotler e Keller (2012) sobre os fatores culturais (cultura, subcultura e classe social), sociais (grupos de referência, família, papéis e status), pessoais (idade e estágio no ciclo de vida, ocupação, situação econômica, estilo de vida, 
Tabela 11: Influência do fator psicológico na escolha dos estudantes.

\begin{tabular}{|c|c|c|c|c|c|c|c|c|c|c|}
\hline \multirow{4}{*}{ VARIÁVEIS } & \multicolumn{8}{|c|}{ CURSOS } & \multirow{3}{*}{\multicolumn{2}{|c|}{$\begin{array}{c}\text { TOTAL } \\
\text { Máximo: } 2.690\end{array}$}} \\
\hline & \multirow{2}{*}{\multicolumn{2}{|c|}{$\begin{array}{c}\mathrm{RH} \\
\text { Máximo: } 1.520 \\
\end{array}$}} & \multirow{2}{*}{\multicolumn{2}{|c|}{$\begin{array}{c}\text { FINANÇAS } \\
\text { Máximo: } 410\end{array}$}} & \multirow{2}{*}{\multicolumn{2}{|c|}{$\begin{array}{c}\text { LOGÍSTICA } \\
\text { Máximo: } 460\end{array}$}} & \multirow{2}{*}{\multicolumn{2}{|c|}{$\begin{array}{l}\text { MARKETING } \\
\text { Máximo: } \mathbf{3 0 0}\end{array}$}} & & \\
\hline & & & & & & & & & & \\
\hline & Soma & $\%$ & Soma & $\%$ & Soma & $\%$ & Soma & $\%$ & Soma & $\%$ \\
\hline $\begin{array}{l}\text { Observei diversas vezes as } \\
\text { propagandas sobre a faculdade e elas } \\
\text { me convenceram a me matricular } \\
\text { neste curso. }\end{array}$ & 8890 & 559 & 2221 & 554 & 2252 & 555 & 2214 & 771 & 11.577 & 559 \\
\hline $\begin{array}{l}\text { Conheço pessoas que cursaram esse } \\
\text { curso e conseguiram melhorar sua } \\
\text { situação profissional. }\end{array}$ & 1.047 & 69 & 248 & 60 & 397 & 86 & 291 & 97 & 1.983 & 74 \\
\hline $\begin{array}{l}\text { Existem momentos em que temos } \\
\text { que tomar uma atitude, para não } \\
\text { nos arrependermos depois. Senti que } \\
\text { tinha chegado a minha hora. }\end{array}$ & 11.370 & 990 & 3366 & 889 & 4419 & 991 & 2256 & 885 & 22.411 & 990 \\
\hline $\begin{array}{l}\text { A vida me ensinou que sem } \\
\text { preparação técnica fica difícil o } \\
\text { desenvolvimento profissional. }\end{array}$ & 11.393 & 992 & 3376 & 992 & 4432 & 994 & 2270 & 990 & 22.471 & 992 \\
\hline $\begin{array}{l}\text { Escolhi esse curso por ser mais } \\
\text { acessível do que os outros. }\end{array}$ & 8864 & 557 & 2248 & 660 & 2285 & 662 & 1175 & 558 & 11.572 & 558 \\
\hline Total & 5.564 & 73 & 1.459 & 71 & 1.785 & 78 & 1.206 & 80 & 10.014 & 74 \\
\hline Máximo & 7.600 & & 2.050 & & 2.300 & & 1.500 & & 13.450 & \\
\hline
\end{tabular}

Nota: O termo "soma" refere-se à pontuação obtida por cada variável, considerando uma escala de 10 pontos e o total de respondentes de cada um dos cursos.

personalidade e autoimagem) e psicológicos (motivação, percepção, aprendizagem, crenças e atitudes), assim como da análise dos resultados das avaliações dos estudantes, conclui-se que, de forma geral, o fator pessoal é o que mais influencia os estudantes na escolha de todos os quatro cursos superiores de tecnologia analisados.

O destaque do fator pessoal entre os fatores de influência de escolha dos estudantes permite estreitar as ideias de Kotler e Keller (2012) com a visão de Grewal e Levy (2011), visto que esses últimos afirmam que o consumidor reconhece que tem uma necessidade não satisfeita e quer sair de seu estado de carência para um estado diferente por ele desejado, iniciando-se, dessa maneira, o processo de decisão de compras.

Ainda sobre a predominância do fator pessoal sobre outros fatores, confirmam-se as ideias de Lovelock (2006), Hoffman (2003), Zeithaml e Bitner (2003), Las Casas (2007) e Bateson e Hoffman (2001) sobre a proposta de que a escolha de uma instituição de ensino para realizar o curso superior na grande maioria dos casos é uma decisão de compra em situação de alto envolvimento.

Ao considerar os resultados encontrados, associado ao expressivo crescimento dos cursos superiores de tecnologia, abordado no referencial teórico deste trabalho, este estudo contribui para que os mantenedores e gestores das IES privadas brasileiras passem a entender melhor os fatores decisivos para a tomada de decisão de seus clientes, para a manutenção e o desenvolvimento de seus negócios.

Embora os procedimentos metodológicos tenham atendido ao propósito desta pesquisa, há limitações que devem ser apontadas, tais como a impossibilidade de generalização de resultados, uma vez que se trabalhou com uma amostra suficiente para a aplicação da análise estatística, porém, oriunda de uma única instituição de ensino. Tal limitação não invalida nossas conclusões e representam hipóteses para novas e futuras pesquisas. 


\section{REFERÊNCIAS}

BATESON, J. E. G.; HOFFMAN, K. D. Marketing de serviços. 4 ed. São Paulo: Artmed, 2001.

BRASIL. Lei nº 9394 de 20 de dezembro de 1996.

. Conselho Nacional de Educação (CNE/CP). Parecer n. 29/2002. Brasília: 02 de dezembro de 2002.

Ministério da Educação. Decreto nº 2.208 de 17

de abril de 1997.

. Ministério da Educação. Instituto Nacional de Estudos e Pesquisas Educacionais Anísio Teixeira (Inep). Censo da educação superior. Brasília, DF: Inep, 2012. Disponível em: <http://portal.inep.gov.br. Acesso em 18 fev. 2014.

Ministério da Educação. Portaria n 1024/2006. Disponível em: <http://mecsrv70.mec.gov.br/catalogo_cursos/ index.php?pagina=portaria_1024>. Acesso em 09 jun. 2014.

ENGEL, J. F.; BLACKWELL, R.D.; MINIARD e PAUL W. Comportamento do Consumidor. São Paulo: Pioneira Thomson Learning, 2005.
GREWAL, D.; LEVY, M. Marketing. Porto Alegre: Bookman, 2011.

HOFFMAN, K. D. Princípios de Marketing de Serviços: Conceitos, Estratégias e Casos. São Paulo: Thomson Learning, 2003.

KOTLER, P.; KELLER K. L. Administração de Marketing. 14. Ed. São Paulo: Prentice Hall, 2012.

LAS CASAS. A. L. Marketing de Serviços. São Paulo: Atlas, 2007.

LOVELOCK, C. H. WRIGHT, L. Serviços: marketing e gestão. São Paulo: Saraiva, 2006.

SANTOS, A. R. Metodologia Científica: a construção do conhecimento. Rio de Janeiro DPeA, 2002.

ZEITHAML, V.; BITNER, M. J. Marketing de Serviços: a Empresa com Foco no Cliente. 2. ed. São Paulo: Bookman, 2003. 